\title{
The Impact Of Faculty Apparel In The Classroom
}

William A. Dowling, (Email: William.Dowling@Savstate.edu), Savannah State University

$\mathscr{I}$ $\mathrm{n}$ addition to imbuing students with traditional field based knowledge, faculty in colleges of business administration have increasingly been asked to instill a sense of professionalism in students. Faculty members are, at the least, expected to bring a sense of professionalism to the classroom, and it is understood that this starts with professional dress on the part of faculty. A concomitant assumption with the expectation of professional behavior and dress on the part of faculty, is the belief that faculty dress has a positive impact on the classroom environment - thus on learning. The literature discussing the interaction of faculty image on the classroom commences with a reference to Workman ${ }^{1}$, who found that faculty who dressed professionally were viewed as creditable. Further, administrators viewed professionally dressed faculty as "overwhelmingly" professional, responsible, and confident. The obvious lesson being that if one wanted to increase their employability, then they should dress professionally. In fact, common advice for new faculty has been found to include pointers on the impact of dress on classroom management ${ }^{2}$.

There have been studies that have examined the impact of faculty attire on perceptions of teaching competence held by students ${ }^{3}$. Others have examined the impact of attire on credibility, likeability, interpersonal attractiveness, and dominance ${ }^{4}$. According to Gorham, Cohen and Morris, studies of student perceptions related to faculty apparel suggest that apparel does impact perceptions. In that apparel that increases the perception of "coolness" on the part of the faculty member decreases the student perceptions of "personal attractiveness" and women are more perceptive to apparel than are men ${ }^{5}$. Gorham, Cohen and Morris cite Rollman's work in which he demonstrated that students' perceptions based solely on apparel differ markedly. Specifically, two pictures of the same faculty member were shown students with the only difference being the apparel. Faculty members in casual apparel were viewed by students as more friendly, more flexible, more sympathetic, more fair and more enthusiastic than those formally dressed.

Faculty members dressed formally were perceived as being- better organized, more knowledgeable, and better prepared than those in casual apparel ${ }^{6}$. It is appropriate to note that these inferences were based on student perceptions of faculty where the students were only shown pictures of faculty - these perceptions were not the result of actual classroom interactions. Further, these outcomes were only student perceptions not measurements of the impact on student learning.

In 1996, Morris, Gorham, Cohen, and Huffman made an attempt to address this issue when they measured student perceptions of guest lecturers? 7 . The guest lecturers were graduate students. The "guests" lectured to different sections of a university level, multi-sectioned, introductory course using the same lecture so that the only variable was apparel. They found that casual apparel for male guest lecturers led to higher scores on perceptions of

\footnotetext{
${ }^{1}$ Workman, J. E. (1984). Effects of appropriate and inappropriate attire on attributions of personal dispositions. Clothing and Textile Research Journal, 3(1), 20-23.

${ }^{2}$ Effects of graduate teaching assistant attire on student learning, misbehaviors, and ratings of instruction. K David Roach. Communication Quarterly University Park: Summer 1997. Vol. 45, Iss. 3, p. 125-141 (17 pp.)

${ }^{3}$ Chowdhary, 1988; Morris, Gorham, Cohen, \& Huffman, 1996; Roach, 1997

${ }^{4}$ Molloy (1988), Raiscot (1986)

${ }^{5}$ Fashion in the classroom III: Effects of instructor attire and immediacy in natural classroom interactions. Joan Gorham, Stanley H Cohen, Tracy L Morris. Communication Quarterly University Park:Summer 1999. Vol. 47, Iss. 3, p. 281299 (19 pp.)

${ }^{6}$ Ibid

${ }^{7}$ Morris, T. L., Gorham, J, Cohen, S.H., \& Huffman, D. (1996). Fashion in the classroom: Effects of attire on student perceptions of instructors in college classes. Communication Education, 45, 135-148.
} 
sociability, extroversion and the judgment that their's (casual apparel) was the most interesting presentation. Formal apparel was only associated with higher competency ratings for females. Based on the results of this study, a faculty member would be well advised to emulate the pro-typical "Maynard G. Crebb's" professorial model. Again, it is appropriate to point out that this was an experiment of limited duration (one guest lecture), not the result of a semester's (or any other grading period's) duration.

In 1977, Gorham, Cohen, and Morris repeated the 1996 study with consideration of faculty immediacy (Immediacy behaviors are those that promote physical and psychological closeness between interactants - is the faculty member perceived as approachable?). Their purpose was to test whether or not instructor immediacy might have overwhelmed the impact of apparel that was reported in their 1996 paper. So they included faculty immediacy as an independent variable since all "guest lecturers" in their 1996 study were viewed as immediate. Thus, the 1997 work used two independent variables and looked at their impacts alone and together on student learning outcomes ${ }^{8}$. Gorham, Cohen and Morris's results indicated that instructor immediacy was indeed the major factor influences student perceptions about classroom interactions. The influence of apparel was limited to perceptions of faculty extroversion in that those casually dressed faculty were viewed as more extroverted than those faculty formally dressed. That is, a strategic choice of apparel did not improve student perceptions of non-immediate faculty or that casual apparel negatively impacted perceptions of immediate faculty ${ }^{9}$.

In 1977, Roach published the results of a study examining the impact of faculty apparel in the classroom. Roach's results found positive, statistically significant correlations between instructor apparel and student perceptions in that faculty dressed in a highly professional fashion (in the opinion of the student) were judged more favorably than either those dressed in a moderately professional fashion or those judged to be dressed in a low professional fashion ${ }^{10}$.

In their 1999 article, Gorham, Cohen and Morris noted that the discrepancy between their results and those of Roach might be due to the lack of control of the apparel variable ${ }^{11}$. Whereas Roach allowed student determination of the categorization of faculty apparel, in their previous papers they manipulated the style of faculty apparel.

Gorham, Cohen and Morris designed their 1999 study to examine the impact of apparel and/or immediacy over a wider range of faculty at two points in time, the first class meeting and midterm. Citing the work of Hoult, the authors speculated that the effects of apparel and/or immediacy would be minimized as students accumulate additional observations on which they will base their perceptions of faculty ${ }^{12}$. The results of this study find that there is little association between perceptions and apparel and the authors conclude that the conventional wisdom of encouraging professional dress is of little value.

None of the literature reviewed measured the differential impact on student learning. Rather, what was measured was the differential impact on student impressions and according to Gorham, Cohen and Morris, "professional dress" makes little difference. Nevertheless, to date it has not been determined whether or not faculty apparel impacts student learning. Further, many (particularly administrators) believe that there is a link between faculty apparel and measures of faculty performance. For faculty members, the measurement of the impact of such

\footnotetext{
${ }^{8}$ Again, for the purposes of this research, it is appropriate to note that the time period used as the basis for determination was one lecture period.

${ }^{9}$ Morris, T. L., Gorham, J, Cohen, S.H., \& Huffman, D. (1996). Fashion in the classroom: Effects of attire on student perceptions of instructors in college classes. Communication Education, 45, 135-148.

${ }^{10}$ Effects of graduate teaching assistant attire on student learning, misbehaviors, and ratings of instruction, K David Roach.

Communication Quarterly University Park: Summer 1997. Vol. 45, Iss. 3, p. 125-141 (17 pp.)

${ }^{11}$ Fashion in the classroom III: Effects of instructor attire and immediacy in natural classroom interactions, Joan Gorham, Stanley H Cohen, Tracy L Morris. Communication Quarterly University Park:Summer 1999. Vol. 47, Iss. 3, p. 281299 (19 pp.)

${ }^{12}$ Hoult, T.F (1954). Experimental measurement of clothing as a factor in some social ratings of selected American men. American Sociological Review, 19, 326-327.
} 
behaviors has all too often been proxied through the use of student assessment measures. As a result, faculty assessment is a fact of life on most college campuses. Arguably, the intent of such programs is to improve instruction in the classroom through faculty development. Thus, on most college campuses, a component of faculty development is an assessment regime. The majority of assessment programs include as a component some form of student assessment of the faculty member teaching the class. These assessments are, for the most part, given significant weight in annual assessment despite their limitations. The literature on student assessment is replete with studies examining the impact of various factors on student assessment. The relationship between student assessment of faculty and student learning has also been examined ${ }^{13,14}$. Nevertheless, an opportunity presents itself to concurrently test the impact of faculty apparel on student perceptions as measured by student evaluations in this research project. However, given the time constraints, results of student assessment of faculty for the fall 2006 Semester will not be available before the scheduled presentation of this paper. Thus the test of the impact of faculty apparel on student assessment of faculty performance is deferred until the results of the longer term study are written up. Therefore for the purpose of this study, the testing hypotheses (H1 and H1A) are proposed:

H1: Faculty apparel makes a significant difference in student learning outcomes.

H1A: Faculty apparel does not make a significant difference in student learning outcomes.

The test was conducted as follows. Four classes offered during the fall 2006 semester in the College of Business Administration at Savannah State University will be used. The classes consisted of two sections of two courses, both of which are required subjects in the BBA program. Specifically, the courses used were Business

Finance (Finc 3155, sections 1 and 2) and Personal Finance (Finc 3000, sections 1 and 2).

To control for differential professorial immediacy, the same faculty member will be used to teach each course. The only difference for the two classes will be that one will be taught by the faculty member in professional dress and the other will be taught by the same faculty member dressed casually. The same lectures and materials will be used in both sections of each course. Further, each course will employ CPS by eInstruction to capture daily assessments of student learning ${ }^{15}$. To control for differences between traditional and non-traditional students, each section that contained mainly traditional students was paired with a section of the same course that contained mainly nontraditional students. Thus, a section of each class offered during the day was paired with a section of the same class offered in the evening. Given the four courses available for study:

Personal Finance Section 1 (Finc 3000.01) (day)

Personal Finance Section 2 (Finc 3000.02) (evening)

Business Finance (Finc 3155.01) (day)

Business Finance (Finc 3155.02) (evening)
Faculty apparel - professional

Faculty apparel - casual

Faculty apparel - casual

Faculty apparel - professional

Further, in this research project, the categorization of faculty apparel is strictly controlled. Retailer, Jos. A. Banks, agreed to sponsor this research by providing and coordinating the faculty apparel using their best

\footnotetext{
${ }^{13}$ It is not the purpose of this paper to include a discussion of the validity of student assessment of faculty nor is it its purpose to reargue the appropriateness of the inclusion of such assessments in measures of the job performance of faculty. Instead, this paper accepts the notions:

(1) that student assessment of faculty exists

(2) there is a presumed relationship between student assessment and student learning

(3) that student assessment is of significance in the career path of faculty (promotion and tenure decisions).

14 Student Evaluations of College Instructors: An Overview by Patricia A. Gordon, Valdosta State University. A paper submitted as partial requirements for PSY 702: Conditions of Learning taught by Dr. William G. Huitt.

${ }^{15}$ CPS is the acronym for the Classroom Performance System, a product of eInstruction.Com. Each student has, as part of their required course materials, an infrared transmitter (in studenteese these are commonly called "clickers"). Each transmitter is uniquely keyed so that the students' responses to in-class queries, in-class exams and even attendance can be monitored and recorded.
} 
interpretation of the currently accepted definition of "professional dress" and "casual dress" based on their sales trends. ${ }^{16}$

\section{DATA}

In the Personal Finance class for the fall 2006 Semester, there were twenty five (25) students in section one and twenty one (21) students in section two. Both sections had a total of twenty four (24) recorded observations. The Business Finance class for the fall 2006 Semester had enrollments of twenty seven (27) in section one and twelve (12) in section two. Both sections of Business Finance had a total of twenty two (22) recorded observations.

The observations for both Personal Finance and Business Finance were with one exception scored events. Some events were pre-tests over assigned materials, some events were inter-temporal assessment questions designed to ascertain whether or not students comprehended materials just covered in class and some of the events were formal assessments (exams). The single exception was the use of attendance as a dependent variable.

The testing methodology employed was a statistical test to determine if the set of scores for sections one and two on any given graded observation were drawn from different populations. That is, as faculty apparel is the variable in question, are the scores from the section where the faculty member is professionally dressed significantly different enough from those where the faculty member is casually dressed so as to imply that the populations are different. Additionally, the attendance records were maintained and a determination of the sameness of population was made based on an attendance variable.

To test for significant difference, a t-Test for difference between 2 independent sample means was used ${ }^{17}$.

\footnotetext{
${ }^{16}$ The benefits of Jos. A. Banks' support are multiple. The most obvious is economic as the costs involved in outfitting the faculty member in currently accepted "professional" dress is not inconsequential. Equally important is the matter of actualizing the concept of "professional" dress to neutralize the tastes, preferences and habits of the 50 something researcher.

${ }^{17}$ The estimated standard error was found by using

$s_{\overline{\mathrm{X}}_{1}-\overline{\mathrm{X}}_{2}}=\sqrt{\frac{s_{1}^{2}}{n_{1}}+\frac{s_{2}^{2}}{n_{2}}}$
}

Given that in the case of the Business Finance Classes, the sample sizes were unequal, a weighted average (a pooled estimate) was employed:

Step 1: pooled variance estimate:

$$
s_{p}^{2}=\frac{\left(n_{1}-1\right) s_{1}^{2}+\left(n_{2}-1\right) s_{2}^{2}}{\left(n_{1}+n_{2}-2\right)}
$$

Step 2: standard error:

$$
s_{\overline{\mathrm{X}}_{1}-\overline{\mathrm{X}}_{2}}=\sqrt{\frac{s_{p}^{2}}{n_{1}}+\frac{s_{p}^{2}}{n_{2}}}
$$

The Statistical Hypotheses is a two-tailed test:

$$
\begin{array}{ll}
\text { H0: } & \mu 1=\mu 2 \\
\text { H1: } & \mu 1 \neq \mu 2
\end{array}
$$

Thus the mean difference will be zero.

$$
\text { H0: } \mu 1-\mu 2=0
$$

$\mathrm{H} 1: \mu 1-\mu 2 \neq 0$

The decision rule used was ( $\operatorname{set} \alpha)$ :

$$
\begin{aligned}
& \text { (a) } \alpha=.05 \\
& \text { (b) two-tailed test } \\
& \text { (c) } \mathrm{df}(\text { Finc3000) }=(\mathrm{n} 1-1)+(\mathrm{n} 2-1)=(25-1)+(21-1)=44 \text {, so the critical value is } \pm 2.0153675 . \\
& \mathrm{df}(\text { Finc3155 })=(\mathrm{n} 1-1)+(\mathrm{n} 2-1)=(27-1)+(12-1)=37 \text {, so the critical value is } \pm 2.026192
\end{aligned}
$$

The computation of the observed $t$ is found by first computing the pooled variance: 


\section{RESULTS $^{18}$}

Table 1 contains the statistics for the mean difference tests for the Personal Finance course (Finc 3000). An inspection of the table reveals that of the twenty four (24) observations, the mean difference was statistically different in eight (8) of the twenty four (24) cases. That is in the twenty three (23) measured events (recall that attendance was one of the twenty four (24) observations) given that the assumptions of sameness in terms of lectures, students, all else save the apparel of the faculty member, there was a significant measureable difference in student performance in eight (8) of the twenty three (23) trials. Interestingly, the measurable difference was positive in five (5) of the eight (8) cases and negative in the remaining three (3) cases. Where professorial apparel was professional, a positive difference occurs when the performance of the class was superior to that of the class where the professorial apparel was casual. Obviously, the reverse of this would create a negative difference. Overall, thirteen (13) of the (24) differences were negative (54\%). This outcome is little more than what one might expect from the toss of a fair coin, that is chance.

$s_{p}^{2}=\frac{\left(n_{1}-1\right) s_{1}^{2}+\left(n_{2}-1\right) s_{2}^{2}}{\left(n_{1}+n_{2}-2\right)}$

Next we compute the standard error:

$$
S_{\overline{\mathrm{X}}_{1}-\overline{\mathrm{X}}_{2}}=\sqrt{\frac{s_{p}^{2}}{n_{1}}+\frac{s_{p}^{2}}{n_{2}}}
$$

The computation of the $t$ is found by:

$$
t=\frac{\left(\overline{\mathrm{X}}_{1}-\bar{X}_{2}\right)-\left(\mu_{1}-\mu_{2}\right)}{s_{\bar{x}_{1}-\bar{x}_{2}}}
$$

The necessary assumptions for t-test with 2 independent samples:

1. The 2 populations from which the samples were selected are normally distributed - this assumption can be violated with few consequences if samples are large.

2. The 2 populations from which the samples were selected have equal variances that is there is an assumption of the "Homogeneity of variance" If the two sample sizes are equal or are close to equal, one sample variance can be up to 4 times the amount of the other with no cause for concern If the sample sizes are quite disparate, then the difference between the variances should be very close to zero or this assumption will be violated. Lastly, if one sample variance is more than 4 times the size of the other, the assumption is likely violated (regardless of sample size)

This note was adapted from Fundamental Statistics for the Behavioral Sciences, 5th Edition by David C. Howell ISBN10: 0534399517, 2004.

${ }^{18}$ Microsoft Excel was used to generate the results. 
Table 1

Personal Finance (Finance 3000)

Probabilities That Sample Means Are From The Same Population

\begin{tabular}{cccc}
\hline Observation & t Stat & t Critical two-tail & P(T<=t) \\
\hline 1 & 0.70724835 & 2.0153675 & 0.483141 \\
2 & 2.27960695 & 2.0153675 & 0.027535 \\
3 & 2.27960695 & 2.0153675 & 0.027535 \\
4 & -3.75436772 & 2.0153675 & 0.000506 \\
5 & 2.01901491 & 2.0153675 & 0.049604 \\
6 & -0.50424084 & 2.0153675 & 0.616608 \\
7 & -0.27621783 & 2.0153675 & 0.783674 \\
8 & 0.67523023 & 2.0153675 & 0.503063 \\
9 & 0.19142441 & 2.0153675 & 0.849074 \\
10 & -0.70998691 & 2.0153675 & 0.481458 \\
11 & -2.30030398 & 2.0153675 & 0.026231 \\
12 & 2.22335382 & 2.0153675 & 0.031375 \\
13 & -1.33744499 & 2.0153675 & 0.18795 \\
14 & 0.93140642 & 2.0153675 & 0.356726 \\
15 & 0.93140642 & 2.0153675 & 0.448799 \\
16 & -2.11451526 & 2.0153675 & 0.040173 \\
17 & -2.29283228 & 2.0153675 & 0.026695 \\
18 & -0.9010161 & 2.0153675 & 0.372485 \\
19 & -1.06835393 & 2.0153675 & 0.291187 \\
20 & -0.14466775 & 2.0153675 & 0.885634 \\
21 & -2.3498601 & 2.0153675 & 0.023331 \\
22 & -0.21304613 & 2.0153675 & 0.832275 \\
23 & -1.59428528 & 2.0153675 & 0.118197
\end{tabular}

The attendance variable, represented in observation 24 is consistent with the majority of outcomes from the other observations, in that there is a negative difference that is not significant at the $5 \%$ level.

Chart 1 in the Appendix paints a slightly different picture but in this case, what is displayed is the probability that the samples were drawn from the same population, thus a significant negative difference and an equal but significantly positive difference would plot identically.

Table 2 summarizes the statistics for the mean difference tests for the Business Finance course (Finc 3155). An inspection of the table reveals that of the twenty two (22) observations, the mean difference was statistically different in only two (2) of the twenty two (22) cases. That is in the twenty one (21) measured events (recall that attendance was one of the twenty two measurements); there was a significant difference in fewer than ten percent of the trials. Further, in contrast to what was found in the Personal Finance class, a negative difference in this class indicates that the performance of the class where the professorial attire was professional exceeded that of the class where the professorial attire was casual. The performance differential was negative, that is, the class where professional attire was present performed at a higher level in nine (9) of the twenty one (21) measured events (43\%). This is close to the percentage observed in the Personal Finance Class (46\%) for the presence of professional attire. 
Table 2

Business Finance (Finance 3155)

Distribution of Probabilities that Means are from Different Populations

\begin{tabular}{cccc}
\hline Observation & t Stat & t Critical two-tail & P(T<=t) \\
\hline 1 & 0.960509 & 2.026192 & 0.343034 \\
2 & 0.986593 & 2.026192 & 0.33025 \\
3 & 0.380771 & 2.026192 & 0.33025 \\
4 & 0.157017 & 2.026192 & 0.876085 \\
5 & -0.01762 & 2.026192 & 0.986038 \\
6 & -1.31649 & 2.026192 & 0.196108 \\
7 & 0.433923 & 2.026192 & 0.666864 \\
8 & 3.295372 & 2.026192 & 0.002173 \\
9 & 2.743382 & 2.026192 & 0.009321 \\
10 & -1.24054 & 2.028094 & 0.222798 \\
11 & -0.32485 & 2.026192 & 0.747126 \\
12 & -1.26933 & 2.026192 & 0.212251 \\
13 & -1.2869 & 2.026192 & 0.206124 \\
14 & 0.232987 & 2.026192 & 0.817055 \\
15 & -0.02027 & 2.026192 & 0.983936 \\
16 & 0.354985 & 2.026192 & 0.724616 \\
17 & -0.3177 & 2.026192 & 0.752501 \\
18 & 0.539645 & 2.026192 & 0.592675 \\
19 & -1.75364 & 2.026192 & 0.087774 \\
20 & 0.460189 & 2.026192 & 0.648073 \\
21 & 0.083077 & 2.026192 & 0.934238 \\
22 & 1.230608 & 2.026192 & 0.226236
\end{tabular}

The attendance observation was positive (casual attire had higher attendance) but the difference was insignificant as was the case with the Personal Finance class.

Chart 2, like Chart 1, plots significant differences (both positive and negative) in the same fashion. The fact that only three of the measurements would be significant at the ten percent level (in contrast to eight in Chart 1 for Personal Finance) is interesting but the distribution contains only two (2) outcomes indicating that casual attire makes a difference versus one (1) indicating a preference for professional attire on the part of the students.

Interpretation of Results, Conclusions, Limitations and Future Research:

The original purpose was to test whether or not professional attire made a significant difference in learning outcomes. Based on the time series analysis of measured outcomes, simply put, there is not a significant difference in performance at any reasonable level of significance. Actually, there is faint support for the contention that casual attire may be preferable. Anecdotal evidence seems consistent with the notion that students are more comfortable (that is they relate more easily to the instructor - better instructor immediacy) to the instructor used in this test when he was attired casually. Admittedly, there are certain advantages for professional attire. However, the suggestion that it makes a difference in student learning outcomes was not supported by this research.

As was stated initially, these are preliminary results from a two semester study. Further, student assessment of faculty data was not available in time to be included in this paper so the final outcome is as yet unknown, but one might well expect it to be little different than the results reported here.

The faculty member participating in this study was a "senior" faculty member who had been part of the core of teaching faculty at Savannah State University for ten years. Thus, he was reasonably well known as a senior member of the faculty of the College of Business Administration. It is typical to associate or make the assumption that maturity implies "creditability". Given the "maturity" of the faculty member in question and the fact that his "reputation" and his projected degree of "immediacy" was well known to students and did indeed precede him in the 
class, there is a reasonable suspicion of a biased outcome. To what extent the results were influenced by this is unknown but one direction for additional research would be to test whether or not these results are influenced by this. To test this, one might repeat the experiment using a newly minted faculty member whose "creditability" or "reputation" and whose degree "immediacy" is unknown to students. Based on the literature, there is support for the notion that professional attire might well infer some degree of "creditability" to the faculty member but whether this would translate into measureable differences in student learning outcomes is unknown. The gender of the faculty member participating in the study was male. Does gender in addition to maturity, tenure and immediacy play a role? The last issue that needs to be considered is the degree of "comfortableness" existent on the part of the faculty member. If one is not accustomed to dressing professionally, then this discomfort may well indeed impact the way in which the faculty member behaves, thus impacting the outcome.

There are always questions that remain and in this case there are numerous unanswered questions. Additionally, there are many potentially confounding issues that remain to be addressed. These issues and questions notwithstanding; based on the results as reported here, when the question is asked, does faculty apparel make a significant measureable difference in student learning outcomes? The answer at this point, is no.

\section{BIBLIOGRAPHY}

1. Chowdhary, U. 1988. Instructor's attire as a biasing factor in students' ratings of an instructor. Clothing and Textiles Research Journal, 6(2), 17-22.

2. Gordon, Patricia. Student Evaluations of College Instructors: An Overview, Valdosta State University. A paper submitted as partial requirements for PSY 702: Conditions of Learning taught by Dr. William G. Huitt.

3. Gorham, J., Cohen, S. H., \& Morris, T. L. (1997). Fashion in the classroom II: Instructor immediacy and attire. Communication Research Reports, 14, 11-23.

4. Gorham, J., Cohen, S.H., Morris, T.L. (Summer 1999). Fashion in the classroom III: Effects of instructor attire and immediacy in natural classroom interactions Communication Quarterly University Park: Summer 1999. Vol. 47, Iss. 3, p. 281-299 (19 pp.)

5. Hoult, T.F (1954). Experimental measurement of clothing as a factor in some social ratings of selected American men. American Sociological Review, 19, 326-327.

6. Howell, David C. Fundamental Statistics for the Behavioral Sciences, 5th Edition, Thomson, ISBN10: 0534399517, 2004.

7. Malloy, J. 1988. John T. Molloy's New Dress for Success. New York, NY: Warner.

8. Montell, Gabriela (2003). Do Good Looks Equal Good Evaluations?.The Chronicle of Higher Education, Wednesday, October 15, 2003

9. Morris, T. L., Gorham, J, Cohen, S.H., \& Huffman, D. (1996). Fashion in the classroom: Effects of attire on student perceptions of instructors in college classes. Communication Education, 45, 135-148.

10. Raiscot, J. (1983). Jury selection, body language, and the visual trial. Minneapolis: AB Publications. Raiscot, J. (1986). Silent sales. Minneapolis: AB Publications.

11. Roach, K. David, (Summer 1997). Effects of graduate teaching assistant attire on student learning, misbehaviors, and ratings of instruction. Communication Quarterly University Park: Summer 1997. Vol. 45, Iss. 3, p. 125-141 (17 pp.)

12. Saiki, Diana (2006). Communication Effectively: Teaching Lessons About Dress for the Workplace. Journal of Family and Consumer Sciences Education, Vol. 24, No. 1, Spring/Summer 2006

13. Workman, J. E. (1984). Effects of appropriate and inappropriate attire on attributions of personal dispositions. Clothing and Textile Research Journal, 3(1), 20-23. 

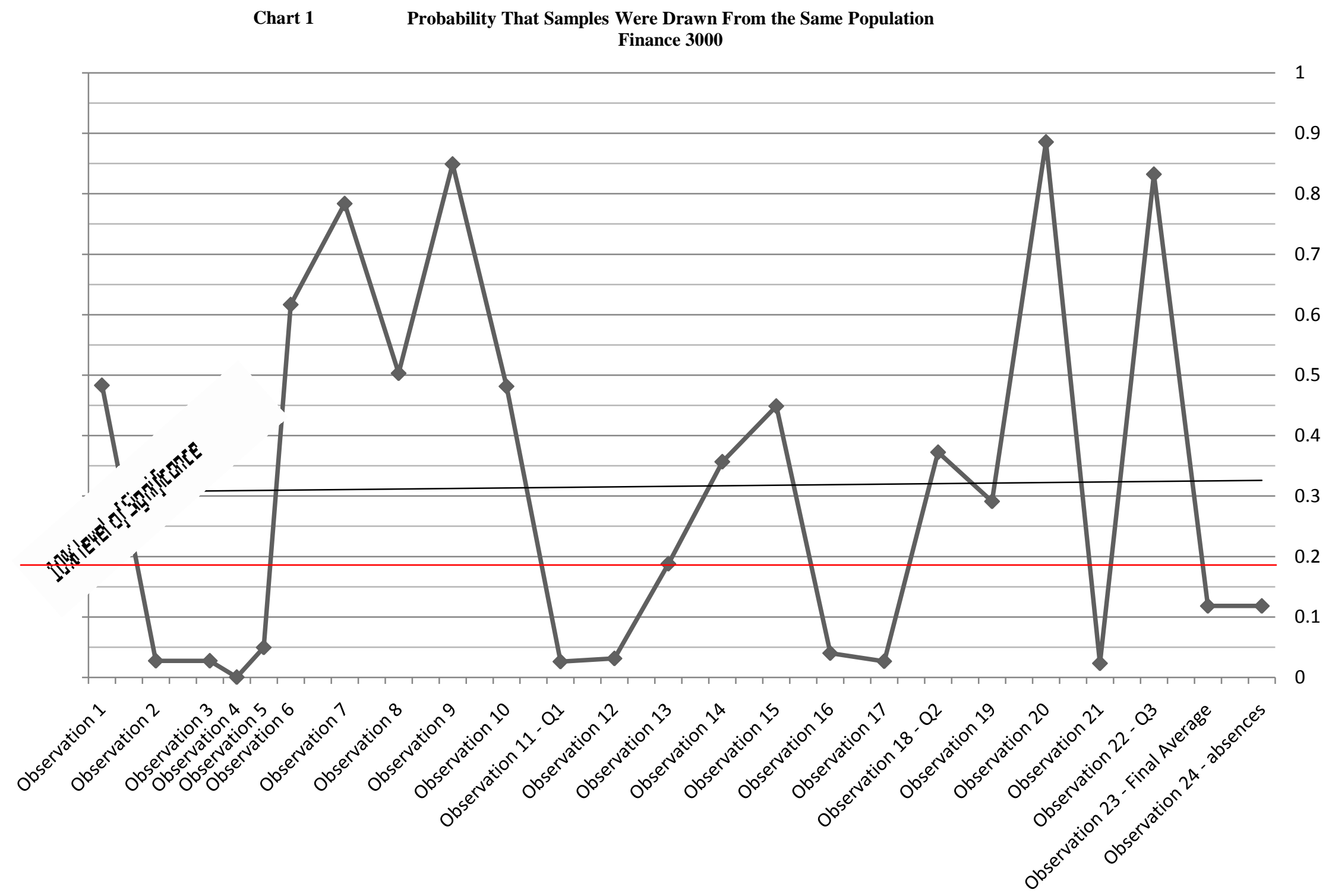
Chart 2

Probability That Samples Were Drawn From The Same Population

Finance 3155

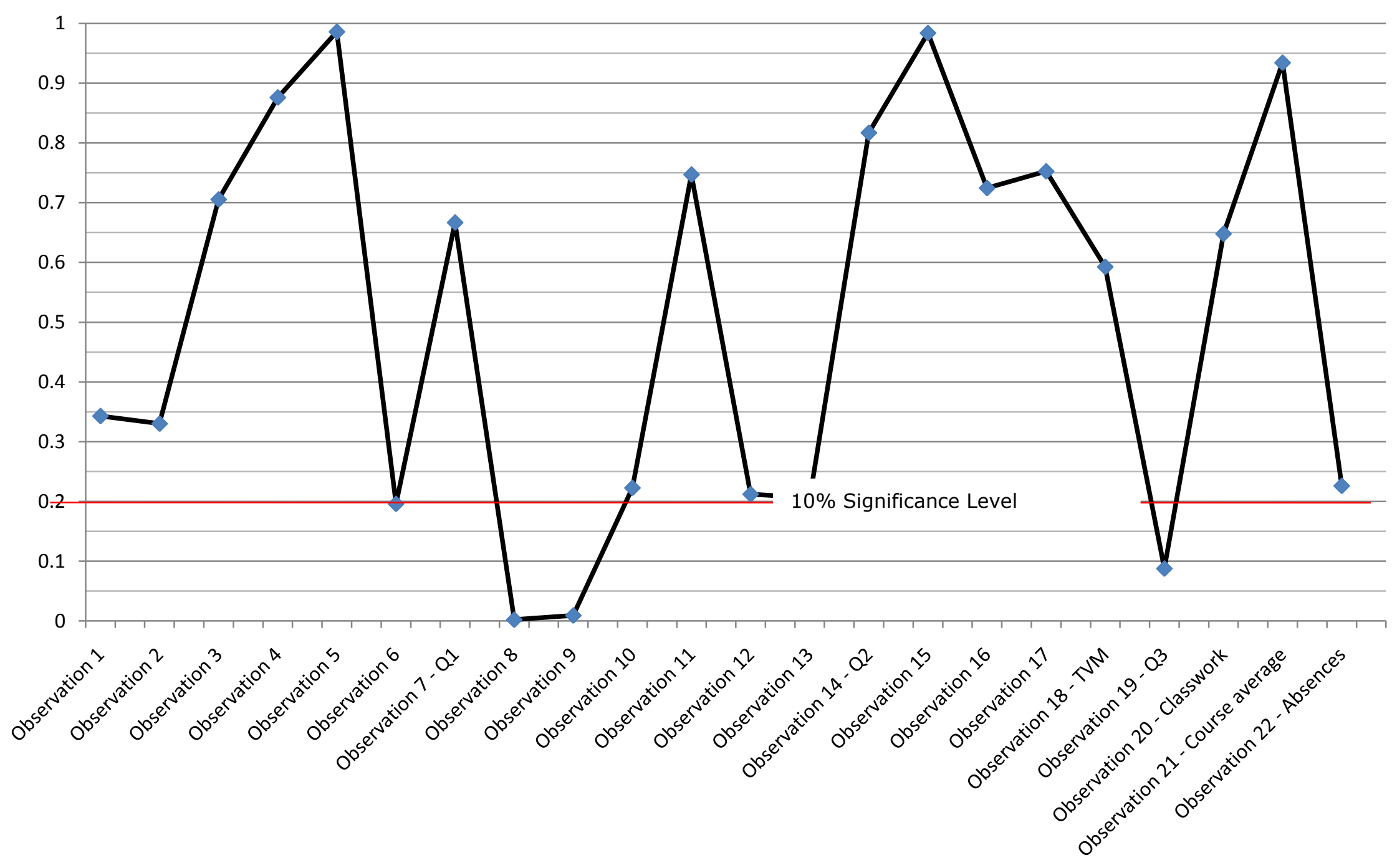


